\title{
Joubert Syndrome Type 7
}

National Cancer Institute

\section{Source}

National Cancer Institute. Joubert Syndrome Type 7. NCI Thesaurus. Code C159653.

An autosomal recessive sub-type of Joubert syndrome caused by mutation(s) in the RPGRIP1L gene, encoding a protein thought to function in programmed cell death. It is characterized by cerebellar and oculomotor apraxia, hypotonia and psychomotor delay, neonatal respiratory abnormalities, renal abnormalities, and retinal dystrophy. 